
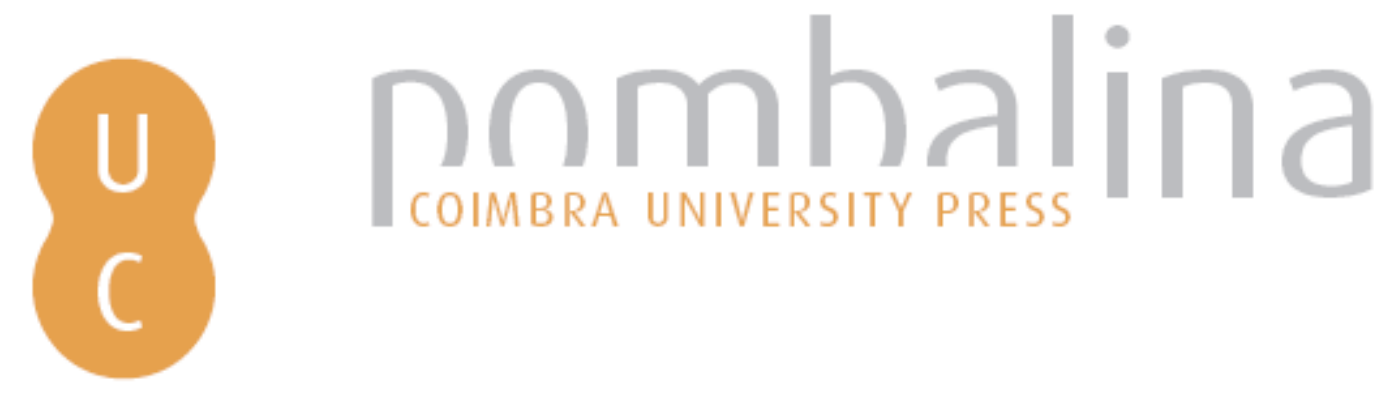

\title{
A influência de conceitos evolucionistas nos primeiros trabalhos de Aurélio Quintanilha (1919-1935)
}

Autor(es): $\quad$ Fonseca, Pedro Ricardo; Pereira, Ana Leonor; Pita, João Rui

Publicado por: Imprensa da Universidade de Coimbra

URL

persistente: URI:http://hdl.handle.net/10316.2/38455

DOI: $\quad$ DOI:http://dx.doi.org/10.14195/978-989-26-0764-1_19

Accessed : $\quad$ 26-Apr-2023 00:51:05

A navegação consulta e descarregamento dos títulos inseridos nas Bibliotecas Digitais UC Digitalis, UC Pombalina e UC Impactum, pressupõem a aceitação plena e sem reservas dos Termos e Condições de Uso destas Bibliotecas Digitais, disponíveis em https://digitalis.uc.pt/pt-pt/termos.

Conforme exposto nos referidos Termos e Condições de Uso, o descarregamento de títulos de acesso restrito requer uma licença válida de autorização devendo o utilizador aceder ao(s) documento(s) a partir de um endereço de IP da instituição detentora da supramencionada licença.

Ao utilizador é apenas permitido o descarregamento para uso pessoal, pelo que o emprego do(s) título(s) descarregado(s) para outro fim, designadamente comercial, carece de autorização do respetivo autor ou editor da obra.

Na medida em que todas as obras da UC Digitalis se encontram protegidas pelo Código do Direito de Autor e Direitos Conexos e demais legislação aplicável, toda a cópia, parcial ou total, deste documento, nos casos em que é legalmente admitida, deverá conter ou fazer-se acompanhar por este aviso.

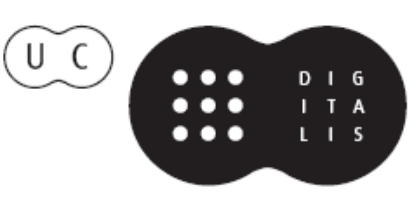


${ }^{1}$ Centro de Estudos Interdisciplinares do Século XX - CEIS20;

Faculdade de Letras da Universidade de Coimbra - FLUC

${ }^{2}$ CEIS20; Faculdade de Farmácia da Universidade de Coimbra

pedrorgfonseca@gmail.com; aleop@ci.uc.pt; jrpita@ci.uc.pt

\section{A Influência de Conceitos Evolucionistas nos Primeiros Trabalhos de Aurélio Quintanilha (1919-1935)}

\section{Pedro Ricardo Fonseca ${ }^{1}$, Ana Leonor Pereira ${ }^{1}$ e João Rui Pita ${ }^{2}$}

"Da fundura do tempo ucrónico, sem duração nem forma,

Rebenta tempo real, tempo de coisas,

E assim a Idade se forma na informação e na contagem.

Do humilde dia astral, já suado no hominídeo

Erguido da brutalidade e do espanto ainda bronco,

O tempo universal encorpa como um tronco.

(...).

Um começo de vida em bando arborícola e alcateia:

O lobo vindo a cão, o homúnculo a hominídeo,

Plantígrado esboçando a estação vertical".

Vitorino Nemésio. 1972. "A Idade do Mundo", In Limite de Idade. Lisboa: Editorial Estúdios- Cor, p. 18-19. Livro de poemas dedicado a Aurélio Quintanilha.

"Não há talvez, no campo da Biologia, questão mais cheia de encantos e atractivos espirituais que esta do estabelecimento das relações filéticas entre os diferentes grupos de seres vivos".

Aurélio Quintanilha. 1926. Contribuição ao Estudo dos Synchytrium (Dissertação para

Doutoramento na Faculdade de Sciências da Universidade de Coimbra).

Coimbra: Imprensa da Universidade, p. 86.

A presente comunicação tem por objectivo principal fornecer uma leitura compreensiva de uma das dimensões do pioneirismo científico-pedagógico de Aurélio Pereira da Silva Quintanilha (1892-1987) na Universidade de Coimbra entre 1919 e 1935. Com efeito, a nossa exposição assenta sobre dois eixos fundamentais: (1) a produção científica de Aurélio Quintanilha durante a sua passagem pela Universidade de Coimbra; e (2) a orientação científico-pedagógica que Aurélio Quintanilha recomendava para o ensino em Portugal. Por economia de espaço, e tendo em conta que, quer o papel de Aurélio Quintanilha na História da Genética em Portugal, quer as suas propostas científico-pedagógicas, se encontram já estudados ${ }^{1}$, optámos por

${ }^{1}$ Vide, por exemplo: ARCHER, Luís 1986. Contribuição para a História da Genética em Portugal. História e 
direccionar a nossa comunicação para um tema que, tanto quanto nos foi possível averiguar, se encontrava ainda por estudar: a influência do evolucionismo na produção científica de Aurélio Quintanilha.

A nossa análise da influência do evolucionismo sobre a produção científica de Aurélio Quintanilha cinge-se a alguns dos trabalhos de sua autoria publicados entre 1921 e 1935, incluindo um trabalho de cariz científico-pedagógico. Antes de iniciarmos a análise, importa introduzir um breve esboço biográfico de um dos mais influentes cientistas portugueses do século XX, que obteve o merecido reconhecimento internacional por parte da comunidade científica da época pelas suas importantes investigaçōes ao nível da genética e da citologia². Aurélio Quintanilha nasceu no dia 24 de Abril de 1892 na Ilha Terceira (Açores). Após uma passagem por Coimbra, onde concluiu os preparatórios para Medicina (1912), mudou-se para Lisboa. Na capital, frequentou a Faculdade de Medicina, antes de resolver mudar de curso e se licenciar em Ciências Histórico-Naturais pela Faculdade de Ciências. No ano em que concluiu a licenciatura (1919), Quintanilha, respondendo favoravelmente ao convite que lhe fora endereçado por Luís Wittnich Carrisso (1886-1937), regressa a Coimbra para leccionar e conduzir as suas investigações no Instituto Botânico. Em Coimbra, concorreu também à Escola Norma Superior, tendo realizado exame de Estado em 1921 - apresentando a dissertação Educação de hoje, educação de Amanhã. No ano de 1926 doutorou-se com a tese Contribuição ao Estudo dos Synchytrium ${ }^{3}$ e concorreu para Professor Catedrático com a tese O Problema das Plantas Carnivoras... ${ }^{4}$. Entre 1928 e 1930, trabalhou no Pflanzenphysiologisches Institut (Berlim) sob a direcção do micologista Hans Kniep (1881-1930), e, entre 1930 e 1931, estagiou no Kaiser Wilhelm Institut für Biologie, sob a direcção do zoólogo Max Hartmann (1876-1962). Regressado a Coimbra, em Maio de 1935, Aurélio Quintanilha seria aposentado compulsivamente do lugar de Professor Catedrático, por motivos político-ideológicos. Em Janeiro de 1936, beneficiando de uma bolsa de estudo atribuída pelo governo da Grã-Bretanha, Quintanilha partiu para França, prosseguindo a sua carreira científica no Museu de História Natural de Paris. Após uma passagem pela Estação Agronómica Nacional (1941-1943), foi nomeado Director do Centro de Investigação Científica Algodoeira em Moçambique em 1943. Na antiga colónia portuguesa, foi várias vezes

Desenvolvimento da Ciência em Portugal. Lisboa: Academia das Ciências de Lisboa, pp. 1027-1067; QUINTANILHA, Aurélio. 1975. História da Genética em Portugal. Brotéria - Série de Ciências Naturais XLIV -(LXXI), vols. 3-4, pp. 189-208; GOMES, Amélia Filomena de Castro 2005. A educação libertária segundo Aurélio Quintanilha. Dissertação de mestrado apresentada à Universidade do Minho.

${ }^{2}$ Embora ainda não tenha sido publicada nenhuma biografia de Aurélio Quintanilha, a sua vida encontra-se bem documentada em vários trabalhos. Vide, entre outros: FERNANDES, Abílio. 1988. Lembrando o Prof. Doutor Aurélio Quintanilha. Brotéria Genética IX - (LXXXIV), 3: 135-150; SERRA, José Antunes. 1988. Professor Aurélio Quintanilha - Impressōes e recordações pessoais de homenagem. Brotéria Genética IX - (LXXXIV), vol. 3, pp. 9-17; NEVES Maria Luísa 1992. Homenagem a Aurélio Quintanilha. Lisboa: Câmara Municipal de Lisboa; MACHADO António de Barros 1993. Aurélio Quintanilha. Algumas Recordações do Mestre, do Cidadão e do Amigo. Brotéria Genética XIV - (LXXXIX), 1-2, pp. 33-41.

${ }^{3}$ QUINTANILHA, Aurélio, 1926. Contribuição ao Estudo dos Synchytrium (Dissertação para Doutoramento na Faculdade de Sciências da Universidade de Coimbra). Coimbra: Imprensa da Universidade.

${ }^{4}$ QUINTANILHA, Aurélio, 1926. O Problema das Plantas Carnívoras. Estudo Citofisiológico da Digestão no Drosophyllum Lusitanicum (Dissertação para Concurso ao Magistério da Faculdade de Sciências). Coimbra: Imprensa da Universidade. 
convidado para dar algumas lições na Universidade de Lourenço Marques. Após o 25 de Abril de 1974, Aurélio Quintanilha regressou a Portugal para dar a sua última lição na Universidade de Coimbra e em 1982 fixou-se definitivamente no nosso país. Quintanilha faleceu no dia 27 de Junho de 1987 com 95 anos de idade.

$\mathrm{Na}$ dissertação que apresentou no âmbito do exame de Estado da Escola Normal Superior de Coimbra, em 1921, Aurélio Quintanilha apresentou um conjunto de medidas que, na sua opinião, contribuiriam para melhorar e alargar as competências do ensino liceal em Portugal, como, por exemplo: um ensino mais centrado nos interesses dos alunos; a aposta em aulas práticas; a implementação do ensino profissional; a introdução de educação cívica e moral. No caso concreto do ensino da biologia, Quintanilha defendia que os alunos deveriam ter um contacto directo com diferentes seres vivos, com o intuito de "criar o gôsto pela observação da vida dos animais, base indispensável para o despertar da curiosidade científica, do desejo de saber como é, e porque é (...)" ${ }^{\prime 6}$. Além disso, e com enorme relevo para o nosso objecto de estudo, recomendava a utilização das relações de parentesco entre espécies (com um antepassado comum relativamente recente) como um instrumento pedagógico. Por exemplo, "se o curso assistiu, ansioso, ás peripécias da caçada de um ratito, por um gato de poucos mêses, graciosíssimo de maneiras e atitudes, que excelente ocasião para the falar da vida dos grandes felinos!"'. Quintanilha sugeria que o professor aproveitasse essa oportunidade para, através de uma história sobre um tigre, transmitir informações aos alunos sobre a biologia desse "rial primo" 8 do gato.

Aurélio Quintanilha reservou um lugar de relevo para os problemas filogenéticos na sua dissertação de doutoramento de 1926. Logo na "Introdução", o cientista português sublinhou a importância dos estudos comparativos e a centralidade das questôes do foro evolucionista:

“(...) a simples verificação da existência de determinados caracteres morfológicos em uma dada espécie, é sempre insuficiente para a interpretação do significado de tais caracteres. De modo que não há outro remédio senão comparar a espécie que estudamos com outras, primeiro do mesmo género, depois da mesma família e assim sucessivamente, se quisermos fazer uma idea tão exacta quanto possível do valor morfológico a atribuir a cada um dos caracteres observados. Insensivelmente começam a estabelecer-se as homologias e, sem a gente dar por isso, lá estamos caídos no magno problema filogenético"

No entanto, os estudos comparativos, por si só, revelavam-se insuficientes porque “(...) o exame dos caracteres morfológicos não é suficiente para a destrinça das

${ }^{5}$ A sessão foi promovida por Abílio Fernandes (1906-1994), antigo aluno e discípulo de Aurélio Quintanilha na Universidade de Coimbra. Vide: QUINTANILHA, Aurélio, 1975. Quatro gerações de cientistas na história do Instituto Botânico de Coimbra. Anuário da Sociedade Broteriana, vol. XLI, pp. 27-44.

${ }^{6}$ QUINTANILHA, Aurélio 1921. Educação de hoje, Educação de amanhãa (Dissertação para o Exame de Estado da Escola Normal Superior de Coimbra). Coimbra. Edição do Autor, p. 7 (Sublinhado do autor).

${ }^{7}$ Idem, ibidem, p. 13.

${ }^{8}$ Idem, ibidem, p. 14.

${ }^{9}$ Idem 1926. Contribuição ao Estudo dos Synchytrium (Dissertação para Doutoramento na Faculdade de Sciências da Universidade de Coimbra). Coimbra: Imprensa da Universidade, p. 3. 
espécies"10. Por outro lado, uma correcta classificação dos Synchytrium teria de dar “(...) uma idea justa do grau de parentesco entre os quatro géneros (...)"11 que formavam o grupo. De acordo com Aurélio Quintanilha, tal classificação poderia vir a ser possível com o avanço dos estudos de citologia: "Quanto aos caracteres tirados da evolução citológica destas formas, êsses sim, que nos haviam de fornecer directrizes seguras para um agrupamento racional e scientífico das espécies de Synchytrium. Infelizmente, porém, pouquíssimas têm sido cuidadosamente estudadas sob esse ponto de vista" ${ }^{12}$. Neste sentido, o autor sublinhou a necessidade de se efectuarem os referidos estudos, enfatizando, simultaneamente, as potencialidades de uma das suas áreas de formação preferenciais (a citologia) para o aperfeiçoamento do processo de classificação das espécies:

"Emquanto se não fizer para a maioria das espécies o que vimos fazendo com o nosso S. papillatum, a resolução do problema filogenético há-de necessàriamente ser tentada às apalpadelas, como se andássemos jogando a "cabra cega». A-pesar-de reduzidas e manifestamente insuficientes, têm sido as investigações citológicas e o conhecimento, delas resultante, da evolução nuclear, que têm permitido (...) estabelecer pontos de contacto e graus de parentesco para fora das fronteiras do género" ${ }^{13}$.

Ao longo da sua dissertação, Aurélio Quintanilha foi abordando com frequência a questão filogenética. Na passagem que se segue, o cientista português sublinhou a importância do seu trabalho de investigação para a questão da filogenia dos Synchytrium:

"Sem entrarmos, por agora, na discussão do problema das relaçōes do género Synchytrium com os outros seres vegetais ou animais, recordemos desde já que todas as soluções até hoje propostas admitem a proveniência necessária destas formas de outras de vida aquática, saprófitas ou parasitas. Os Synchytrium podem pois ser considerados como parasitas primitivos de plantas aquáticas que gradual e progressivamente se foram adaptando, com os seus hospedeiros, a uma vida anfibia, com períodos de emersão cada vez mais largos, até que lhes foi possível viver sobre plantas essencialmente terrestres, nunca imersas e apenas de longe em longe banhadas pela água das chuvas ou neves. Assim, a existência de geraçóes sucessivas de soros esporângios, formas essencialmente de multiplicação, entre dois períodos de repouso, é uma característica da vida aquática, que se mantém nos parasitas de hospedeiros sujeitos a longos períodos de imersão (S. taraxaci p. ex.) e desapareceu por completo nas formas mais perfeitamente adaptadas à vida terrestre.

O nosso $S$. papillatum fornece um argumento valioso em auxílio desta tese. Vivendo, entre nós, sobre um hospedeiro normalmente emerso e que dispõe apenas, nos seus órgãos aéreos, da água das precipitaçôes atmosféricas, as suas formações de germinação imediata encontram-se em manifesto declínio, pois aparecem em percentagem insignificante relativamente às formas de repouso, mesmo na época do ano mais favorável para o seu desenvolvimento. Se atendermos a que tal facto se não dá, por exemplo, no $S$. taraxaci e no $S$. endobioticum, aonde os soros

\footnotetext{
${ }^{10}$ Idem, ibidem, p. 64.

${ }^{11}$ Idem, ibidem, p. 72.

${ }^{12}$ Idem, ibidem, p. 76.

${ }^{13}$ Idem, ibidem, p. 77.
} 
de esporângios são abundantíssimos, pelo menos durante toda a primavera; se atendermos ainda a que no $S$. decipiens nem sequer se conhecem esporos de resistência, tendo-se encontrado apenas até hoje soros de esporângios, a nossa doutrina aparece assente em muito fortes probabilidades de verossimilhança.

Admitida esta hipótese, como a mais lógica dentro do estado actual dos nossos conhecimentos, a existência de sucessivas gerações de soros esporângios, no decurso de um mesmo período vegetativo, não pode ser considerada carácter de primacial importância filogenética. A existência ou a ausência deste tipo de órgãos de multiplicação indicar-nos-há o grau de adaptação às condições de vida das plantas permanentemente emersas e a antiguidade relativa da fase de transição da vida aquática para a vida terrestre"14.

Embora em “(...) discordância com opiniōes expostas por investigadores que do género se têm ocupado" ${ }^{15}$, Aurélio Quintanilha incluía a espécie S. endobioticum nos Synchytrium. O autor justifica a sua decisão com motivos do foro filogenético: "Alem de que o seu ciclo evolutivo se adapta inteiramente (...) ao conceito histórico do género, a sua colocação junto das outras espécies de Synchytrium vem preencher uma vaga e facilitar a compreensão das afinidades e relações de parentesco dêste grupo de fungos"16. Uma vez mais em discordância com outros estudiosos do género, Quintanilha reservava " (...) um lugar aparte, fora da linha de derivação filogenética das formas superiores do género" 17 à espécie $S$. fulgens, devido à excepcionalidade do seu modo de germinação; e coloca “(...) o S. Wurthii nos Mesochytrium, como forma de transição para os Pycnochytrium"18. Ainda sobre as formas de transição, um tema clássico do evolucionismo, Aurélio Quintanilha informa-nos que "Como tipos de transição entre as formas inferiores e superiores do grupo [dos Synchytrium] aparecem-nos o S. stellariae e o $S$. succisae (Mesochytrium), com caracteres mixtos entre os Eusynchytrium e os Pycnochytrium ${ }^{19}$. Um dos caracteres que distinguia as formas superiores das formas inferiores era a formação exógena dos soros das primeiras. No entanto, Aurélio Quintanilha, sublinhando agora a importância da adaptação ao meio, informa-nos que: “(...) a formação exógena dos soros não é apenas um carácter de maior complexidade morfológica. A aquisição dêste processo representa, em nossa opinião, uma vantagem para a disseminação da espécie, que facilmente se pode relacionar com a adaptação à vida terrestre" ${ }^{20}$.

No subcapítulo "Distribuïção geográfica e lugar de origem”, Aurélio Quintanilha avança com questôes de teor evolucionista: “¿Que planta deve ser considerada como hospedeiro primitivo do $S$. papillatum? ¿Qual o lugar de origem do fungo e como se explica a sua actual distribuïção geográfica?”21. Mas é no último capítulo, intitulado

${ }^{14}$ Idem, ibidem, pp. 77-78 (ênfase do Autor).

${ }^{15}$ Idem, ibidem, p. 82.

${ }^{16}$ Idem, ibidem, pp. 83-84 (ênfase do Autor).

${ }^{17} \mathrm{Idem}$, ibidem, p. 84.

${ }^{18} \mathrm{Idem}$, ibidem, p. 84.

${ }^{19} \mathrm{Idem}$, ibidem, p. 80.

${ }^{20}$ Idem, ibidem, p. 79. Aurélio Quintanilha aborda outras questôes relacionadas com a adaptação ao meio ao longo da sua tese de doutoramento. Vide, por exemplo: Idem, ibidem, pp. 63, 66-67, 79, 85.

${ }^{21}$ Idem, ibidem, p. 68. 
"Posição e afinidades dos Synchytrium", que ele se ocupa, quase exclusivamente, de questôes do foro evolucionista. O capítulo abre com algumas considerações elucidativas da influência que o evolucionismo exerceu sobre o trabalho científico de Aurélio Quintanilha:

"Não é nossa intenção tratar aqui desenvolvidamente o problema, extraordinariamente complexo, das relaçôes do género Synchytrium com os outros organismos animais ou vegetais.

Para empresa de tamanha responsabilidade nos faltam, antes de mais nada, competência e autoridade, qualidades estas que só se conquistam ao cabo de longos anos de investigações especializadas e pelo conhecimento directo da maioria dos grupos com os quais se podem presumir relações filéticas.

Consideramos porém indispensável, como remate lógico dêste trabalho, expor a traços largos o que se pensa da posição e afinidades dos Synchytrium e em que é que as nossas investigações podem contribuir para [o] esclarecimento do problema"22.

Um contributo que se afigurava ainda mais urgente, pois, como o próprio Aurélio Quintanilha nos informa, no caso dos fungos “(...) o problema das origens e relaçôes se apresenta particularmente complicado" ${ }^{23}$. Depois de realizar uma exposição sobre algumas das principais perspectivas evolucionistas sobre os Synchytrium, Quintanilha apresenta a sua própria perspectiva "(...) sôbre a posição e afinidades dos Synchytrium" 24 . A passagem que se segue revela-nos um naturalista versado na linguagem evolucionista e profundamente conhecedor da discussão em torno da história evolutiva dos Synchytrium:

"Os que aceitam como boa a doutrina de que os Archimycetes devem ser considerados como formas de regressão dos Phycomycetes superiores, derivam estes, por sua vez, de diferentes grupos de algas verdes (...). A-pesar-do diplanetismo dos zoósporos dos Phycomycetes (...) e das diferenças, por vezes consideráveis, que se encontram quando se cortejam os vários orgãos dêstes grupos de plantas, ficam ainda, entre os respectivos ciclos evolutivos, tamanhas analogias, que é dificil admitir que umas e outras se tenham originado e evoluído independentemente, que tais semelhanças sejam o resultado fortuito de uma simples evolução paralela em análogas condições mesológicas. (...).

Todavia, mesmo que tenhamos de admitir a doutrina da filiação, total ou parcial, dos Phycomycetes superiores, nos grupos mais altamente diferenciados de Clorofíceas, ou nas Conjugadas, isso não implica de nenhum modo concordância com a segunda parte da hipótese. Os Archymycetes não podem ter derivado, por regressão, dos Oomycetes e Zygomycetes (...). Ou o grupo dos Phycomycetes deve ser encarado como um todo homogéneo, monofilético, que, partindo de organismos inferiores, evoluíu pelos Archimycetes até aos Oomycetes e Zygomycetes; ou devemos considerá-lo como um agregado heterogéneo, polifilético, de dois ou mais grupos diferentes, cada um dêles com a sua linhagem independente. (...).

Nós vamos mesmo mais longe, e afirmamos que o trabalho de Griggs nos conduz necessariamente a rejeitar, por impossível, a idea de uma aproximação filética entre os Archimycetes e as Protococcaceae. (...).

\footnotetext{
${ }^{22}$ Idem, ibidem, p. 86.

${ }^{23}$ Idem, ibidem, p. 86.

${ }^{24}$ Idem, ibidem, p. 95.
} 
A hipótese de derivação dos Archimycetes (pelos Synchytrium) e das Protococcaceae (pelas Phyllobiae) a partir de antepassados próximos comuns, deve também ser posta de parte.

A idea da aproximação dos Esporozoários, lançada, ao que parece, por Haeckel (...), parece-nos, pelo contrário, assente em bases mais seguras, ainda que não conheçamos directamente os trabalhos modernos sôbre a citologia dêstes micro-organismos" ${ }^{25}$.

Com efeito, Aurélio Quintanilha afirma que:

"Não concluímos (...) pela derivação dos Synchytrium a partir de qualquer das ordens de Esporozoários, mas sim pela existência de um tronco comum aos dois grandes grupos de micro-organismos"26.

Significativamente, o cientista português chama a nossa atenção para a circunstância de o seu trabalho de investigação ter vindo a lançar luz sobre a história evolutiva dos Synchytrium:

"As nossas investigações sôbre a citologia dos Synchytrium e, particularmente, a descoberta de uma divisão nuclear de tipo mixto, partilhando ao mesmo tempo dos caracteres da mitose e da amitose (...) provam (...) a existência de um parentesco muito estreito entre as Synchytriaceae e as Plasmodiophoreae - precisamente o grupo de Monadineae que daquelas parecia mais afastado" 27 .

Quintanilha substancia as conclusões apresentadas:

“(...) conhecemos perfeitamente a citologia das Plasmodiophoreae, não só pela leitura dos mais importantes trabalhos originais que têm aparecido, mas ainda pelas nossas próprias investigações sôbre a Plasmodiophora brassicae Wor.

Podemos assim afirmar que entre o ciclo evolutivo das Plasmodiophoreae e o dos Synchytrium existem importantes pontos de contacto; e as divergências que se encontram podem atribuir-se, ou a um conhecimento imperfeito de todo o ciclo evolutivo (particularmente no que respeita aos Synchytrium), ou a adaptações secundárias a diferentes condições mesológicas"28.

De resto, a conclusão da sua dissertação de doutoramento sublinha, de forma inequívoca, a centralidade atribuída a questões do foro evolucionista:

"Em conclusão: Os Synchytrium constituem um género tão isolado no seio dos Archimycetes, que devemos considerá-los como representantes únicos da família das Synchytriaceae. O seu ciclo evolutivo e as minúcias de ordem citológica que o acompanham permitem a aproximação do género, por um lado, dos Esporozoários e, por outro, das Plasmodiophoreae; e dão foros de verossimilhança à hipótese da existência de um tronco comum de micro-organismos flagelados,

\footnotetext{
${ }^{25}$ Idem, ibidem, pp. 96-97.

${ }^{26}$ Idem, ibidem, p. 98.

${ }^{27}$ Idem, ibidem, p. 99.

${ }^{28}$ Idem, ibidem, p. 100.
} 
parasitas de vida aquática, de onde teriam derivado em séries divergentes os Esporozoários, as Plasmodiophoreae e os Archimycetes"29.

Em 1926, Aurélio Quintanilha apresentou a sua dissertação O Problema das Plantas Carnivoras... no âmbito do concurso a Professor Catedrático da Faculdade de Ciências da Universidade de Coimbra. Na "Breve introdução histórica" dos estudos sobre as plantas carnívoras, Quintanilha informa-nos que:

"Até 1875, data em que Darwin publica a primeira edição das «Insectivorous Plants», nada mais aparece digno de menção especial. Os poucos trabalhos publicados são observações fragmentárias, sem pontos de vista de conjunto, e vêm a lume em pequenas revistas e jornais de reduzida tiragem; de modo que não conseguem chamar a atenção do grande público, nem mesmo a dos meios scientíficos.

Assim, a obra magistral de Darwin deve ser considerada como o ponto de partida do estudo metódico e scientífico da carnivoria. Concebida em largos moldes, por um altíssimo espírito, amplamente culto, fruto de pacientes e demoradas observações, a obra do grande naturalista inglês carreou tal número de conhecimentos novos e maravilhosos, teve tamanha repercussão nos meios cultos, que por êsse mundo fora tôdas as atenções convergem sôbre êste novo e inesperado aspecto do problema da nutrição, em que os papéis aparecem, como que por milagre, invertidos, e uma pléiade brilhante de investigadores se lança no caminho desvendado pelo Mestre.

Para Darwin, que estudou quási tôdas as plantas hoje consideradas como insectívoras, a nutrição carnívora era um facto incontestável. Se não tôdas, pelo menos a maioria, segregavam fermentos digestivos do tipo da pepsina, que, em meio ácido, dissolviam as substâncias albuminóides, levando-as a um estado em que podiam ser absorvidas pela planta. Estudou muito pormenorizadamente a mobilidade dos aparelhos de captura de várias insectívoras, determinando com grande precisão o grau de extrema sensibilidade de alguns, tanto a excitações de ordem química como de ordem meramente mecânica. Ligou uma atenção muito particular aos fenómenos celulares que acompanham a digestão e a absorção pelas glândulas digestivas, tendo criado o têrmo "agregação" para designar o estado das células glandulares, ou do pedúnculo dos tentáculos, após determinadas excitações ou depois da absorção de certas substâncias”30.

As referências à "obra magistral de Darwin" de 1875 sucedem-se ao longo da exposição ${ }^{31}$, com Aurélio Quintanilha a lembrar que "O estudo citológico das glândulas das plantas carnívoras tem sido abordado, a partir da publicação do trabalho de Darwin em 1875, por naturalistas da categoria de De Vries, Goebel, Huie e França, para não citar senão os mais eminentes" 32 . De resto, uma das problemáticas centrais do trabalho de Aurélio Quintanilha foi identificada pela primeira vez pelo próprio "Mestre", Charles Darwin:

${ }^{29}$ Idem, ibidem, pp. 102-103.

${ }^{30}$ QUINTANILHA, Aurélio. 1926. O Problema das Plantas Carnivoras. Estudo Citofisiológico da Digestão no «Drosophyllum Lusitanicum (Dissertação para Concurso ao Magistério da Faculdade de Sciências). Coimbra: Imprensa da Universidade, pp. 4-5.

${ }^{31}$ Idem, ibidem, pp. 18, 20, 24-25. Na secção da bibliografia surge a obra de 1875 no original inglês: "Darwin, C. 1875. «Insectivorous Plants,» London, 1875”, p. 70.

${ }^{32}$ Idem, ibidem, p. 33. 
"Um outro problema porém fica de pé, aguardando uma solução definitiva, a-pesar-de Darwin o ter entrevisto (...).

Se o Drosophyllum digere os albuminóides e absorve os produtos da digestão ¿que papel representam neste fenómeno os seus dois tipos de glândulas?"33.

A importância da obra de 1875 de Charles Darwin e a admiração que Aurélio Quintanilha manifesta pelo "grande naturalista inglês" são aspectos relevantes do seu trabalho. Igualmente relevante é a explicação para o surgimento da "carnivoria" avançada por Quintanilha, mostrando uma vez mais a sua familiaridade com a linguagem evolucionista:

"A carnivoria aparece pois com o aspecto de uma adaptação primitiva, anterior à diferenciação dos caracteres florais que determinaram a formação dos géneros. Nascida de uma necessidade comum a tôda uma família, implantou-se aproveitando configurações as mais variadas do aparelho vegetativo, que se acentuaram depois, no decurso da evolução, em direcções diferentes ab initio ${ }^{34}$. O autor apresentou mesmo um esboço faseado da evolução das plantas carnívoras: "Devemos, por isso, considerar a carnivoria acidental como uma primeira étape na adaptação das plantas holofíticas a êste tipo particular de nutrição. A segunda étape seria representada pelas carnívoras sem fermentos digestivos. A terceira, pelas carnívoras que digerem sem intervenção de organismos estranhos, por meio de fermentos que elas próprias elaboram" 35 .

Tal como para as plantas carnívoras em 1926, também em 1932-33, ${ }^{36}$ Aurélio Quintanilha avança com um esboço da história evolutiva dos Basidiomicetos:

"À partir de formes primitives, avec huit noyaux dans la baside et huit spores, les Basidiomycètes auraient ainsi évolué, vers les formes actuelles, par réduction successive du nombre de spores et, puis, du nombre de noyaux formés dans la baside (...). Si le nombre des noyaux formés est supérieur a celui des spores, et si la détermination du sexe est génotypique, il faut toujours s'attendre à la possibilité de recontrer des formes homothalliques, par suppression de la phase haploïde, conséquence de la migration dans la spore jeune de deux noyaux de sexes différents"37.

No decurso do mesmo trabalho, Aurélio Quintanilha, analisando comparativamente as teorias de determinação sexual de Richard B. Goldschmidt (1878-1958) e de Carl Correns (1864-1933), sublinha a importância destas serem consistentes com os nossos conhecimentos filogenéticos:

"La façon dont Goldschmidt se sert pour faire ses formules a l'avantage, sur celle de Correns, d'être plus simple, plus homogène, puisqu'on peut l'appliquer, dans sa forme fondamentale,

\footnotetext{
${ }^{33}$ Idem, ibidem, pp. 25-26.

${ }^{34}$ Idem, ibidem, p. 15.

${ }^{35}$ Idem, ibidem, p. 21.

${ }^{36}$ Quintanilha, Aurélio. 1932-33. Le problème de la sexualité chez les Basidiomycètes. Recherches sur le genre «Coprinus». Boletim da Sociedade Broteriana VIII, 2º série: 3-99.

${ }^{37}$ Idem, ibidem, pp. 16-17.
} 
à tous les groupes d'animaux et de plantes étudiés sous ce point de vue (...), et celle encore de permettre de mieux comprendre l'évolution phylogénétique des différents groupes d'êtres vivants pour ce qui concerne le développement de la sexualité" 38 . No mesmo sentido, o cientista português, analisando agora as diferentes teorias sobre a determinação sexual ao nível do género Coprinus, sublinha que: "Pour des espèces du même genre nous aurions donc deux types de détermination du sexe tout-à-fait différents et on n'aurait pu expliquer les rélations phylogénétiques évidents entre ces mêmes espèces" 39 .

Concluímos a nossa apresentação com a inclusão de uma passagem de um outro artigo da autoria de Aurélio Quintanilha, que demonstra uma vez mais a influência do evolucionismo sobre a sua produção científica, bem como o seu excelente domínio da linguagem evolucionista:

"Nous savons cependant que chez les Champignons ces organes sexuels tendent à disparaittre, par évolution regressive, et que plusieurs espèces actuelles, dépourvues de ces organes, sont certainement les descendantes d'autres espèces qui en étaient pourvues. C'est le cas de plusieurs Ascomycètes et trés probablement aussi des Basidiomycètes.

Alors les formes homothalliques de Basidiomycètes (type Coprinus sterquilinus) seraient les représentantes actuelles des ancêtres monoïques (type Pyronema confluens), dépourvus de facteurs de stérilité. Les organes sexuels mâles et femelles auraient disparu par évolution regressive et la fécondation se trouveraient ici reduite à un phénomène de somatogamie. Les formes hétérothalliques bipolaires (type Coprinus comatus) auraient leurs correspondantes dans les formes monoïques d'Ascomycètes avec une paire de facteurs de stérilité (type Pleurage anserine). L'hétérothallie bipolaire se serait ainsi dévelopée progressivement à partir de formes primitives homothalliques. Ces formes primitives possèderaient les potences des deux sexes et pourraient ainsi produire des organes mâles et femelles, autofertiles. La disparition des organes sexuels par évolution régressive aurait été ici accompagnée de l'introduction d'une paire de facteurs de stérilité $(A a)^{40}$.

\section{REFERÊNCIAS}

ARCHER, Luís - "Contribuição para a História da Genética em Portugal". História e Desenvolvimento da Ciência em Portugal. Lisboa: Academia das Ciências de Lisboa (1986), p. 1027-1067.

FERNANDES, Abílio - Lembrando o Prof. Doutor Aurélio Quintanilha. Brotéria Genética. IX (LXXXIV) (1988), Vol. 3. p. 135-150.

GOMES, Amélia Filomena de Castro - A educação libertária segundo Aurélio Quintanilha. [S.l.]: Universidade do Minho, 2005. Dissertação de mestrado apresentada à Universidade do Minho.

MACHADO, António de Barros - Aurélio Quintanilha. Algumas Recordações do Mestre, do Cidadão e do Amigo. Brotéria Genética. XIV (LXXXIX) Vol. 1-2 (1993), p. 33-41.

NEMÉSIO, Vitorino - A Idade do Mundo. In Limite de Idade. Lisboa: Editorial Estúdios Cor, 1972.

NEVES, Maria Luísa - Homenagem a Aurélio Quintanilha. Lisboa: Câmara Municipal de Lisboa, 1992.

QUINTANILHA, Aurélio - Educação de hoje, Educação de amanhã. Coimbra, 1921. 44f. Dissertação para o Exame de Estado da Escola Normal Superior de Coimbra.

\footnotetext{
${ }^{38}$ Idem, ibidem, p. 72.

${ }^{39}$ Idem, ibidem, p. 80.

${ }^{40}$ QUINTANILHA, Aurélio 1935. Cytologie et génétique de la sexualité chez les Hyménomycètes. Boletim da Sociedade Broteriana X, 2. ${ }^{a}$ série: 289-332, pp. 322-323.
} 
QUINTANILHA, Aurélio - Contribuição ao Estudo dos Synchytrium. Coimbra: Imprensa da Universidade, 1926. 110 p. Dissertação para Doutoramento na Faculdade de Sciências da Universidade de Coimbra.

QUINTANILHA, Aurélio - O Problema das Plantas Carnívoras. Estudo Citofisiológico da Digestão no «Drosophyllum Lusitanicum. Coimbra: Imprensa da Universidade, 1926. 88 p. Dissertação para Concurso ao Magistério da Faculdade de Sciências.

QUINTANILHA, Aurélio - Le problème de la sexualité chez les Basidiomycètes. Recherches sur le genre «Coprinus». Boletim da Sociedade Broteriana. 2.a série. VIII (1932-33), p. 3-99.

QUINTANILHA, Aurélio - Cytologie et génétique de la sexualité chez les Hyménomycètes. Boletim da Sociedade Broteriana. 2. a série. X (1935), p. 289-332.

QUINTANILHA, Aurélio - História da Genética em Portugal. Brotéria. Série de Ciências Naturais XLIV -LXXI. Vols. 3-4, p. 189-208.

QUINTANILHA, Aurélio - Quatro gerações de cientistas na história do Instituto Botânico de Coimbra. Anuário da Sociedade Broteriana. Vol. XLI (1975), p. 27-44.

SERRA, José Antunes - Professor Aurélio Quintanilha - Impressōes e recordações pessoais de homenagem. Brotéria Genética. IX (LXXXIV) (1988), Vol. 3. p. 9-17. 